\title{
The Application of Salutogenesis in Everyday Settings
}

\author{
Georg F. Bauer
}

\section{Introduction}

Settings are defined as "the place or social context in which people engage in daily activities in which environmental, organizational, and personal factors interact to affect health and wellbeing" (WHO, 1998). Such settings as place or social space range, e.g., from small-scale home/family to (international) organizations and large cities and thus differ in size, in their degree of formalized organization, and their relationships to society.

The WHO Ottawa Charta for health promotion (1986) states that "health is created and lived by people within the settings of their everyday life; where they learn, work, play and love" (emphasis added). Thus, this section focuses on these everyday settings in contrast to the section on healthcare settings that are explicitly in charge with dealing with health or rather disease issues. Being aware of the challenge to introduce the health perspective into everyday settings, WHO (http://www.who.int/healthy_settings/types/ en/) and other players have established numerous local, national, and international networks to support and link such efforts, e.g., through the networks of health-promoting schools, universities, cities, and workplaces. Obviously, in context of globalization, the relevance of "non-traditional, non-institutional settings" (Dooris, 2013), e.g., related to social media and virtual communities (Loss, Lindacher, \& Curbach, 2014) need to be also addressed in the future.

The WHO Ottawa Charta (1986) 30 years ago clearly defined that health is a ". . .resource for everyday life .... A positive concept emphasizing social and personal resources, as well as physical capacities .... To reach a state of complete physical, mental and social well-being." Surprisingly, now

G.F. Bauer $(\bowtie)$

Division of Public and Organizational Health, Epidemiology, Biostatistics and Prevention Institute, University of Zürich, Hirschengraben 84, Zürich CH-8001, Switzerland

e-mail: georg.bauer@uzh.ch;http://www.ebpi.uzh.ch the WHO claims that healthy settings focus on risk factors and disease prevention: "Healthy Settings, the settings-based approaches to health promotion, involve a holistic and multidisciplinary method which integrates action across risk factors. The goal is to maximize disease prevention via a 'whole system' approach" (emphasis added) (WHO, 2015). However, as well demonstrated in the chapters enclosed in this section, in practice most scholarship and programmatic approaches regarding health promotion in everyday settings emphasize strengthening resources and promoting health over preventing disease outcomes.

Regarding agency, settings can be perceived as an efficient access for outside agents to large, well-defined target groups for health promotion-typically referred to as "health promotion in settings." Alternatively, external health promotion specialists can build up capacities of inside agents within settings to address behavioral and environmental health issues themselves-typically referred to as "healthpromoting setting."

Overall, the overarching, generic settings literature more or less agrees upon several principles of the settings approach (Dooris, 2005, 2009; Paton, Soumen, \& Lamiece, 2005; Poland, Kurpa, \& McCall, 2009; Shareck, Frohlich, \& Poland, 2013):

\section{- Ecological model of health}

- Taking a whole systems approach considering reciprocal relationships within the system and between its subsystems, as well as relationships with systems in the environment

- Organizational development for change

- Promoting participation as key process of interventions

Surprisingly, this generic literature makes no (Paton et al., 2005; Whitelaw et al., 2001) or only very brief, general references to salutogenesis as a source of inspiration or orientation for the settings approach (e.g., Dooris, 2005, 2009, 2013; Poland et al., 2009). 


\section{Application of Salutogenesis in the Chapters in this Part}

Salutogenesis has been applied to guide health promotion research and practice in various settings. The enclosed chapters review this literature separately for the settings of community/neighborhood, city, restorative environments, school, university, work, workers in prisons, and organizations contained in this section. All these chapters follow a common structure: they describe the context of the particular setting, summarize the descriptive and intervention-related research under consideration of the link to salutogenesis, and finally draw conclusions for future research and practice.

The reader will observe that the degree of application of salutogenesis in these settings highly varies. Much of the setting-related literature is strongly rooted in the general health promotion principles: interventions should be empowering, participatory, holistic, inter-sectorial, equitable, sustainable, and multi-strategy (Rootman, 2001). The literature offers diverse health-related research and sound programmatic approaches-but in most cases only loosely refers to salutogenesis. Some fields such as restorative environments or occupational health developed strong conceptual and empirical knowledge outside the salutogenic model-but can be interpreted within this model. There is only limited research on the setting-specific role of sense of coherence, and even less on other elements of the salutogenic model (e.g., generalized resistance resources, salutary factors, ease-/disease continuum) and of their relationships and dynamics within settings. However, research on designing interventions to actively promote salutogenesis is growing, e.g., in the settings of neighborhoods, schools, worksites, or prisons.

The following subsections identify key relationships between salutogenesis and settings emerging across the chapters on diverse everyday settings. They are based on my subjective reading as the section editor and are offered as an invitation to draw own conclusion on future developments of salutogenesis in context of settings.

\section{Overall Conceptual Relationships Between Everyday Settings and Salutogenesis}

Most of the chapters agree that the settings approach conceptually is in line with salutogenesis-as both imply not to target individuals and single risk factors or disease outcomes, but groups and upstream, environmental determinants of health. Some chapters point out that the resource or asset orientation of the settings approach resonates well with Antonovsky's concern for sense of coherence and generalized resistance resources. As most everyday settings function on the meso-level between the individual and the larger socioeconomic environment, it is reasonable to assume that the generalized resistance resources experienced in interaction with these key life domains are a particularly strong source of sense of coherence. Most settings are characterized by strong social relationships between its members. This suggests to not only study the sense of coherence of individuals in isolation, but the degree of shared perception of a sense of coherence on a group level as proposed by Antonovsky (1987, p. 171).

For the future, the settings approach could offer meaningful categories for classifying generalized resistance resources. First, generalized resistance resources can be grouped by setting, e.g., family, neighborhood, and work. Second, within a setting, subdimensions of these generalized resistance resources can be identified based on key characteristics of the setting. For example, the chapter of work discriminates factual, task-related resources from relational, social resources. The chapter on communities and neighborhoods distinguishes between settings as a place (natural and built environment), identity (sense of community), social entity (cohesion, social capital), and as collective action (reactive-resilience; proactive-community action). Such clearly defined, setting-related categories of generalized resistance resources would allow to study their relative importance for the development of the overall sense of coherence and particularly of the setting-specific sense of coherence. The latter concept refers to the idea that each setting will vary in regard to how comprehensible, manageable, and meaningful it is perceived by its members and customers. Although the setting-specific sense of coherence will partly depend on the overall sense of coherence of a person as a personal resource, it will also depend on settingspecific characteristics and vary for one person across settings. Consequently, earlier we proposed developing setting-specific measures of sense of coherence as indicators of the salutogenic, interactional quality of a specific setting (Bauer \& Jenny, 2007). For now, this idea has been applied to the work-related sense of coherence (Bauer, Vogt, Inauen, \& Jenny, 2015; Vogt, Jenny, \& Bauer, 2013) and before to the University SOC (Graeser, 2011).

\section{Interrelationships Between Settings from a Salutogenic Perspective}

The idea of setting-specific generalized resistance resources and sense of coherence raises the interesting research question of how they influence each other across settings and how they differentially contribute to development of generic sense of coherence and health. Whereas most of the enclosed 
chapters treat the various everyday settings separately from each other, some reflect on such relationships between life domains.

Maass et al. show that sense of coherence is influenced by different life domains (Maass, Lindstrøm, \& Lillefjell, 2014): the satisfaction with the quality of neighborhood resources was significantly related to sense of coherence in non-workers and low-earners-but not for other employed citizens. The authors conclude that deprived groups might benefit most from health promotion in neighborhoods-as they depend more on neighborhood quality. Research on restorative environments looks at the everyday variation of mostly ecological resources due to diverse person-environment interactions during the day-considering both shortterm effects on functioning and long-term, accumulative health effects of these cross-domain dynamics. It shows, for example, that the recovery experience at home can be constrained by demands by work brought home. Most systematically, the cross-environment experience has been studied for the work/non-work relationship. This research has moved from an originally heavily pathogenic focus on work-life conflicts to the more positive processes of worklife enhancement and work-life balance (Greenhaus \& Allen, 2010). From a salutogenic perspective, the experience of balance could be understood as a result of successful balancing stressors and generalized resistance resources experienced across the involved life domains.

Work/non-work-related research is of particular interest as it builds on several overarching theories potentially relevant for salutogenic research within and across settings: for example, conservation of resource theory (Hobfoll, 1989, 2001), work-home resource model (Brummelhuis \& Bakker, 2012), compensation theory, ecological systems theory, social identity theory, or spillover theory (Demerouti, Peeters, \& van der Heijden, 2012; Michel, Mitchelson, Kotrba, LeBreton, \& Baltes, 2009).

\section{Dynamics of Development, Depletion, and Restoration of Generalized Resistance Resources and of sense of coherence}

Antonovsky was primarily interested in long-term development of sense of coherence and thus in long-term effects of generalized resistance resources as well. Following this long-term time frame, the enclosed chapters suggest to particularly look into critical transitions into new life domains or life phases where the challenges might outpace the development of generalized resistance resources, of specific resistance resources or of sense of coherence. Such transitions include entry into the educational system or into the job market, founding a family or reaching retirement.
In addition, several chapters conceptualize and test shortterm dynamics between various generalized resistance resources, sense of coherence, and health. Research on restorative environments studies the daily "dynamics of depletion and renewal of resources needed for the maintenance and promotion of health and well-being" (Von Lindern, Lymeus, and Hartig, this volume). It offers several theories explaining the restorative processes, such as the psychophysiological stress recovery theory or attention restoration theory. According to this theory, an environment is restorative if it is "rich in fascinating features, is perceived as coherently ordered and of substantial scope, and is compatible with what the individual wants to do." These characteristics seem to strongly overlap with the comprehensibility and meaningfulness dimension of sense of coherence. Von Lindern, Lymeus, and Hartig point out that this theory could allow to study if a low sense of coherence is due to initially low generalized resistance resources or due to a persistent lack of restoring overused resources.

In the work setting, the effort-recovery theory looks at the day-to-day dynamics of recovery from work-related stress through cognitive-emotional detachment from work. The job demands resource model allows study of the dynamics of job resources, e.g., by disentangling stable and changing parts of job resources over time (Brauchli, Schaufeli, Jenny, Füllemann, \& Bauer, 2013) or by looking into reciprocal relationships of gain and loss cycles between job resources and health outcomes.

\section{Consider Positive Health Outcomes and Path of Positive Health Development}

The chapter on "the salutogenic model of health-development from the early days to 1994" (Vinje et al., this volume) shows that Antonovsky wanted to move beyond categorical disease outcome by introducing the ease-/disease continuum. However, he refrained from defining positive health, partly to avoid the medicalization of health and its potential misuse by power holders. Still, most of the enclosed chapters on everyday settings make the claim that considering positive health outcomes is one of the key criteria for classifying research and practice as salutogenic. As mentioned above, also the WHO Ottawa Charta (1986) defined health positively as "social and personal resources, as well as physical capacities .... to reach a state of complete physical, mental and social well-being."

At the same time, most authors in this section agree that concrete measures of positive health outcome are urgently needed. The chapter on school settings proposes well-being, quality of life, being in control, action competence, and the ability to play and dance as measures of positive health. 
Linking interventions to positive outcomes is also considered to better resonate with often positive everyday experiences of people in settings-a prerequisite for developing ownership of the interventions.

The chapter on restorative environments shows that restoration can be promoted by "allowing people to become positively engaged with pleasantly interesting experiences in the moment ..." (emphasis added). The chapter on salutogenesis at work shows that the job demands resource model emphasizes to study the positive, motivational path from job resources to engagement as a positive outcome in its own right. Further, the chapter illustrates how merging this logic with the generic health development model (Bauer, Davies, \& Pelikan, 2006) results in the job demands resource health model (Brauchli, Jenny, Füllemann, \& Bauer, 2015). This model suggests the simultaneous study of the two parallel paths of job demands leading to disease outcomes (pathogenic path) and of job resources leading to positive health outcomes (salutogenic path). In the latter case, resources are not only considered to be relevant for coping with life stressors as in the original salutogenic model. Resources are conceptualized and empirically shown to be directly related to positive health outcomes.

\section{Relevance of Social Relationships in Settings: Need for a Group-Level Sense of Coherence in Settings?}

Antonovsky's suggestion to conceptualize and measure sense of coherence on a group level has been repeated by several authors in our section. As summarized in the chapter on "the salutogenic model of health-development from the early days to 1994" (Vinje et al., this volume), Antonovsky's thought that sense of coherence can be an emergent group property in primary groups such as family, neighborhood, or immediate work groups. He defined a group with a strong sense of coherence as "a group whose individual members tend to perceive the collectivity as one that views the world as comprehensible, manageable, and meaningful. . and ... a high degree of consensus in these perceptions" (1987, p. 174). He suggested several preconditions for the emergence of a group sense of coherence: duration of the existence of a collectivity, a group consciousness, overriding centrality in members' life, interwoven self-identity, and social identity. As key mechanism, he assumed that groups with a strong sense of coherence tend to structure situations such that they more likely promote individual sense of coherence and that these groups have the ability to activate its collective resources.

As settings are defined as social systems and as social relationships play a central role in their functioning, this idea of a group sense of coherence seems reasonable. However, at the same time one needs to ask if postulating and measuring a collective sense of coherence adds additional power or meaning for explaining health development in social systems beyond established concepts of social relationships such as social capital, social cohesion, connectedness, social inclusion/exclusion, sense of community, and collective action. In any case, group level health development processes deserve more attention as exemplified in the chapter on restorative environments by the example of collective restoration or in the chapter on salutogenesis at work by the case of shared job resources.

\section{Inclusion and Equity Perspective}

Several chapters make the point that settings are spaces in which diverse groups can be present. This implies to consider differences in health development between groups with different cultural and socioeconomic backgrounds or diverse life stages. At the same time, settings as shared social systems provide opportunities for linkages between and inclusion of such diverse groups, considering interdependencies, e.g., between socioeconomic status, working conditions, quality of family relationships, and quality of neighborhood. Conceptually, such an inclusive perspective is promoted by the whole systems approach of settings as exemplified by whole schools or whole universities. From a salutogenesis perspective, this would imply studying differential, clustered opportunities for generalized resistance resources in various life domains, as well as differences in levels of sense of coherence for socioeconomic subgroups within settings.

\section{Last, Not Least: Salutogenesis for Guiding Interventions in Settings}

Salutogenesis can guide interventions by pointing to generalized resistance resources, sense of coherence, and positive health as key outcomes. The asset orientation is particularly relevant for salutogenic interventions as it refers to the key role of (general resistance) resources that need to be identified and enhanced during interventions. Besides being considered as a key outcome, basic levels of generalized resistance resources and of sense of coherence could be considered as a prerequisite to successfully engage in the intervention process in the first place. The worksite chapter shows that a minimum level of job resources such as social support and recognition facilitates engaging in and benefitting from an intervention (Jenny et al., 2015). As pointed out in the chapter on restorative environment, taking part in interventions by itself requires attention-for example, by acquiring new knowledge and skills. Thus, at least 
initially, interventions could be perceived as additional stressors and add to further depletion of attention resources.

Most chapters agree upon that participatory interventions are needed to assure perceived relevance and ownership of the content of the intervention. The chapter on correction workers points out that participation will lead to increased communication and involvement in decision-making - two processes identified by Antonovsky as particularly relevant for developing a strong sense of coherence. In order to capture simultaneously potential negative and positive characteristics of the intervention process, one could ask participants about the comprehensibility, manageability, and meaningfulness of the intervention. This interventionrelated sense of coherence has been applied in a large-scale stress intervention study in organizations and shown to be positively related to outcome expectancies of the intervention (Jenny et al., 2015). As shown in the chapter of communities and neighborhoods, Bull et al. make a direct link between local development initiatives and sense of coherence: "By mobilizing the capacity and assets of people and places, local development initiatives will make sense logically in the local context (comprehensibility), (...) practically realistic (manageability) and they will be motivating because they are meaningful, based on involvement in decision-making processes (meaningfulness)" (Bull, Mittlemark, \& Kanyeka, 2013, p. 171).

Further, most authors in this section agree that during interventions linkages between the settings of interest and its relevant environments need to be taken into account, as these environments are sources of higher order, upstream health determinants and simultaneously contain external beneficiaries of health promotion interventions. Some chapters indicate that intervention success in one setting might depend on experiences in other settings. The case of community/neighborhoods shows that particularly people with poorer jobs benefit from neighborhood interventions. Research on restorative environments, on effort-recovery and work-life balance all point to developing interventions to improve boundary management skills of people moving through various life domains over a course of the day in order to protect and restore key generalized resistance resources.

\section{Conclusions for Future Research and Practice}

The above review demonstrates that applying salutogenesis to various settings and linking salutogenesis with other models established in these settings has the great potential to generate ideas how to advance the general salutogenic model. First, it seems promising to study more the temporal and spatial dynamics of generalized resistance resources and sense of coherence: short-term, daily changes, and relationships; relationships of generalized resistance resources and sense of coherence across settings; changes of generalized resistance resources; and sense of coherence in life transitions. Second, specifying the salutogenic model for a specific setting allows to select and to study relationships of the salutogenic model particularly relevant to the respective context. The case of the job demands resource health model shows how the pathogenic and salutogenic processes can be related. Third, the salutogenic model could be used for planning interventions that by themselves are comprehensible, manageable, and meaningful and thus support health development. Fourth, everyday settings remind us that life is not only about surviving Antonovskys "toxic river of life." Instead, settings in which people "learn, work, play, and love" are also a key source of positive life experience such as joy, growth, thriving, or flourishing - an emerging new area of research which could lead to an expanded salutogenic model.

Open Access This chapter is distributed under the terms of the Creative Commons Attribution-Noncommercial 2.5 License (http:// creativecommons.org/licenses/by-nc/2.5/) which permits any noncommercial use, distribution, and reproduction in any medium, provided the original author(s) and source are credited.

The images or other third party material in this chapter are included in the work's Creative Commons license, unless indicated otherwise in the credit line; if such material is not included in the work's Creative Commons license and the respective action is not permitted by statutory regulation, users will need to obtain permission from the license holder to duplicate, adapt or reproduce the material.

\section{References}

Antonovsky, A. (1987). Unraveling the mystery of health: How people manage stress and stay well. San Francisco: Jossey-Bass.

Bauer, G. F., Davies, J. K., \& Pelikan, J. (2006). The EUHPID Health Development Model for the classification of public health indicators. Health Promotion International, 21(2), 153-159.

Bauer, G. F., \& Jenny, G. (2007). Development, implementation and dissemination of occupational health management (OHM): Putting salutogenesis into practice. In S. McIntyre \& J. Houdmondt (Eds.), Occupational health psychology. European perspectives on research, education and practice, Vol. 2, European academy of occupational health psychology (EA-OHP). Castelo da Maia: ISMAI.

Bauer, G. F., Vogt, K., Inauen, A., \& Jenny, G. J. (2015). Work-SoCEntwicklung und Validierung einer Skala zur Erfassung des arbeitsbezogenen Kohärenzgefühls. Zeitschrift für Gesundheitspsychologie, 55, 115-131.

Brauchli, R., Jenny, G. J., Füllemann, D., Bauer, G. F. (2015). Towards a job demands-resources health model: Empirical testing with generalizable indicators of job demands, job resources, and comprehensive health outcomes. BioMed Research International http://dx.doi. org $/ 10.1155 / 2015 / 959621$

Brauchli, R., Schaufeli, W. B., Jenny, G. J., Füllemann, D., \& Bauer, G. F. (2013). Disentangling stability and change in job resources, job demands, and employee well-being-A three-wave study on the 
job-demands resources model. Journal of Vocational Behavior, 83 (2), 117-129.

Brummelhuis, L. L., \& Bakker, A. B. (2012). A resource perspective on the work-home interface: The work-home resources model. American Psychologist, 67(7), 545-556.

Bull, T., Mittlemark, M., \& Kanyeka, N. E. (2013). Assets for wellbeing for women living in deep poverty: Through a salutogenic looking-glass. Critical Public Health, 23(2), 160-173.

Demerouti, E., Peeters, M., \& van der Heijden, B. (2012). Work-family interface from a life and career stage perspective: The role of demands and resources. International Journal of Psychology, 47 (4), 241-258.

Dooris, M. (2005). Healthy settings: Challenges to generating evidence of effectiveness. Health Promotion International, 21(1), $55-65$.

Dooris, M. (2009). Holistic and sustainable health improvement: The contribution of the settings-bases approach to health promotion. Public Health, 129(1), 29-36.

Dooris, M. (2013). Expert voices for change: Bridging the silostowards healthy and sustainable settings for the 21 st century. Health \& Place, 20, 39-50.

Graeser, S. (2011). Salutogenic factors for mental health promotion in work settings and organizations. International Review of Psychiatry, 23(6), 508-515.

Greenhaus, J. H., \& Allen, T. D. (2011). Work-family balance: A review and extension of the literature. In J. C. Quick \& L. E. Tetrick (Eds.), Handbook of occupational health psychology (pp. 165-183). Washington, DC: American Psychological Association.

Hobfoll, S. (1989). Conversation of resources. A new attempt at conceptualizing stress. American Psychologist, 44(3), 513-524.

Hobfoll, S. (2001). The influence of culture, community, and the nested-self in the stress process: Advancing conservation of resources theory. Applied Psychology, 50(3), 337-421.

Jenny, G. J., Brauchli, R., Inauen, A., Füllemann, D., Fridrich, A., \& Bauer, G. (2015). Process and outcome evaluation of an organizational-level stress management intervention in Switzerland. Health Promotion International, 30(3), 573-585.
Loss, J., Lindacher, V., \& Curbach, J. (2014). Online social networking sites-A novel setting for health promotion? Health \& Place, 26, 161-170.

Maass, R. E. K., Lindstrøm, B., \& Lillefjell, M. (2014). Exploring the relationship between perceptions of neighbourhood-resources, sense of coherence and health for different groups in a Norwegian neighbourhood. Journal of Public Health Research, 3(1), 208.

Michel, J. S., Mitchelson, J. K., Kotrba, L. M., LeBreton, J. M., \& Baltes, B. B. (2009). A comparative test of work-family conflict models and critical examination of work-family linkages. Journal of Vocational Behavior, 74(2), 199-218.

Paton, K., Soumen, S., \& Lamiece, H. (2005). Settings, systems and organization development the Healthy Living and Working Model. Health Promotion International, 20(1), 81-89.

Poland, B., Kurpa, G., \& McCall, D. (2009). Settings for health promotion: An analytic framework to guide intervention design and implementation. Health Promotion Practice, 10(4), 505-516.

Rootman, I. (2001). Introduction. In I. Rootman et al. (Eds.), Evaluation in health promotion: Principles and perspectives. Copenhagen, Denmark: WHO.

Shareck, M., Frohlich, K. L., \& Poland, B. (2013). Reducing social inequities in health through settings-related interventions-A conceptual framework. Global Health Promotion 1757-9759, 20(2), $39-52$.

Vogt, K., Jenny, G. J., \& Bauer, G. (2013). Comprehensibility, manageability and meaningfulness at work: Construct validity of a scale measuring work-related sense of coherence. SA Journal of Industrial Psychology, 39(1), 8.

Whitelaw, S., Baxendale, A., Bryce, C., Machardy, L., Young, I., \& Witney, E. (2001). 'Settings' based health promotion: A review. Health Promotion International, 16(4), 339-353.

WHO. (1986). The Ottawa charter for health promotion-World 1986 http://www.who.int/healthpromotion/conferences/previous/ottawa/ en/

WHO. (1998). Health promotion glossary. WHO/HPR/HEP/98.1. Geneva.

WHO. (2015). Healthy settings. Retrieved September 24, 2015, from http://www.who.int/healthy_settings/en/ 